\section{Why should doctors look at art? A study of Hokusai's Great Wave}

\author{
John Launer
}

Most of the literature in the field of medical humanities concerns the written word. Only a small proportion addresses the visual arts, examining why doctors might benefit from looking at great pictures or sculptures, as part of their broader education. In this article I want to use one famous image - Hokusai's Great Wave - to demonstrate what you can gain from studying a single work of art closely. I hope to show how doing so can develop your powers of observation, and deepen your understanding of the relationship between what you know and what you see. Before you read any further, I want to invite you to look at the picture itself for as long as you wish, certainly for a minute or two, and possibly longer, if you can spare the time. A reproduction of the picture appears at the end of this article, or you can see one by clicking on the first reference at the bottom of the page. ${ }^{1}$

Almost certainly, the image will be familiar to you, even if you did not know that the artist was known as Hokusai, and that the full name of the picture is 'Inside the hollow of a wave offshore from Kanagawa'. The title appears with his signature at the top left hand corner of the picture. Anyone looking at it in 1831, when it was made, would probably have known that Kanagawa was a fishing port south of Tokyo (then called Edo). The print was made with the traditional method at the time, using a series of carved wooden blocks, and applying one for each colour. Hokusai only used three wood blocks for this picture: black, blue and yellow. Now that you know all these facts, I suggest you to look at the picture once more, and see how this knowledge of the title, location, and Hokusai's technique, has altered your understanding of the picture.

Now, looking away from the picture once more, I want to ask you try and answer some questions from memory. Exactly how many waves are there in the picture, and is the number on the right the same as on the left? Can you describe

Correspondence to Dr John Launer, Faculty Development, Health Education England, Stewart House, 32 Russell Square, London WC1B 5DN, UK: john.launer@nwl.hee.nhs.uk the waves? What is the weather like? What time of day is it, and what time of year? You may find it possible to give one or two answers on the basis of memory alone, and perhaps one or two more by re-examining the picture. For the other answers, you may feel you need some extra information. All the same, I suggest you look at the picture again, trying to deduce what you can, before you move on to the next paragraph.

\section{VISUAL PUNS}

If you look carefully, you will notice there are black lines indicating three waves on the right of the picture. If you then move your gaze over to the left, as a Japanese reader would do, they merge into two waves, indicating that the sea is getting rougher. The top wave is a gigantic one, with the foam on top leaping forward. It is known technically as a plunging breaker. ${ }^{2}$ This is the wave that forms the central hollow we are looking into directly as viewers. In the lower wave, the foam is behaving differently. This is a so-called spilling breaker. It dwarfs Mount Fuji in the background and is, in fact, the shape of the same mountain when seen from a different angle. This is one of a number of visual puns in the print. You may have noticed that the foam on the waves looks like fingers or claws, about to grasp the boats beneath them. The corrugations inside the Great Wave look like the maw of a voracious shark.

No rain is visible, but the waves are ferocious, and the grey clouds above the sea suggest that a storm is rising up. As we are just south of Tokyo, we are facing west. The yellow glow above Fuji, with a darker sky below, therefore probably tells us that the sun has just risen behind us, so it is early morning. You may not happen to know that storm waves of the kind shown are commonest in this part of the Pacific in spring, but if you managed to work this out, you certainly deserve bonus marks! Now look at the three boats carefully. What kind of boats are these, what exactly are the men in them doing, and do you think they are all going to get through the waves safely? Once again, try to answer these questions through observation and deduction alone if you can, before reading on.

If you remembered that the title says they were near a fishing port, you may have been puzzled that there is no evidence that these are fishing boats. In fact, they are fast cargo boats, designed for carrying fish from larger vessels out at sea to the markets on land. These particular boats are empty, apart from a few sacks in the leading boat, so they are presumably on their way to pick up a load from somewhere south, before taking it back to Tokyo in the north. In these kinds of boats, the oarsmen would normally stand. Because of the weather conditions, they have crouched down. They are holding their oars horizontally alongside the boat, to reduce the resistance to the waves. (The lattice pattern on the side of the furthest boat shows the oars pressed up against outrigger bars, which protrude from the boat. The two men who sit in the bows are a relief pair of crew.) Although the size of the Great Wave is higher than the length of a single boat itself around $12 \mathrm{~m}$ - we are probably meant to imagine that the crew know how to navigate these extreme conditions, and will get through. However, because the moment is frozen in time, you never know.

Hokusai had retired before he returned to make a series of views of Mount Fuji, of which this is the first, as well as the best known. He was compelled to work again because he had fallen on hard times. Fortunately, the series of prints made his fortune, and he continued as a successful and productive artist until the age of 88 . It is possible that the Great Wave not only shows a scene Hokusai had witnessed personally, but is symbolic of his personal crisis too. If that is the case, we know that Hokusai passed through it, leaving us an extraordinary record of his powers of close observation and his unbelievable artistry. I hope you agree that he also left us a brilliant example of how the study of art can help doctors to enhance a huge range of our skills: of eyes, memory, deduction, and the ability to use new information to broaden the scope of what we can actually see. Finally, hold the picture upside down, and you will see the iconic symbol of Yin and Yang, representing how light and dark complement each other, and showing how mathematics and science converge with art.

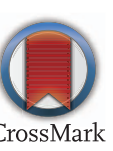




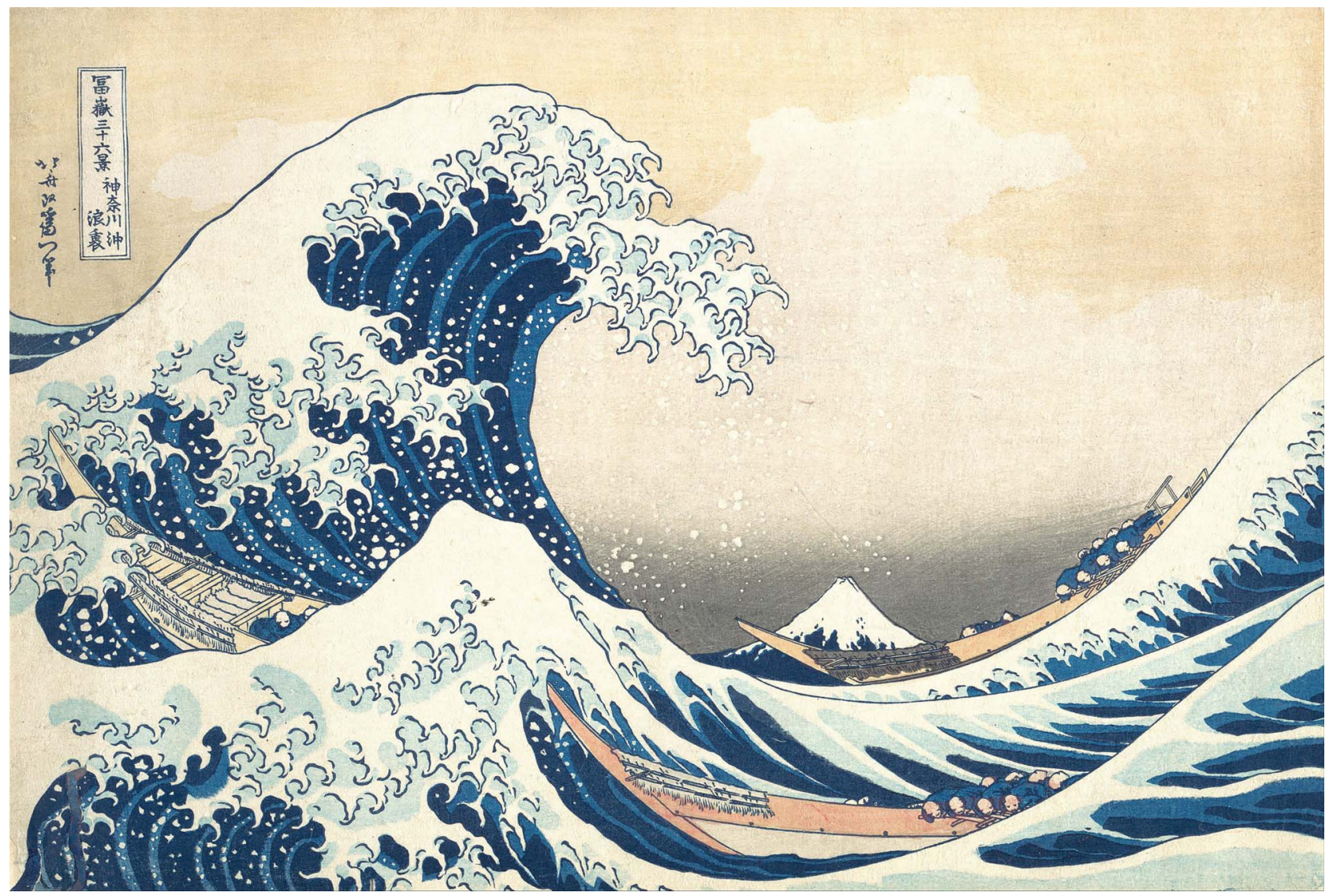

To cite Launer J. Postgrad Med J 2015;91: 536-537.

Postgrad Med J 2015;91:536-537.

doi:10.1136/postgradmedj-2015-133679

\section{REFERENCES}

The Metropolitan Museum of Art. The Collection Online. Katsushika Hokusai Under the Wave off Kanagawa. http://www.metmuseum.org/collection/the-collectiononline/search/45434 (accessed 30 July 2015)
2 Cartwright JHE, Nakamura N. What kind of wave is Hokusai's Great Wave off Kanagawa? Notes Rec $R$ Soc 2009;63:1190135. 